\section{International Scientific Journal Theoretical \& Applied Science}

\author{
p-ISSN: 2308-4944 (print) e-ISSN: 2409-0085 (online) \\ Year: $2017 \quad$ Issue: $06 \quad$ Volume: 50
}

Published: $30.06 .2017 \quad$ http://T-Science.org
Alexey D. Gavrilov

Master student of Political Science Department of International Relations, Political Science and Regional Studies Volgograd State University, Volgograd, Russian Federation

SECTION 22. Policy. Innovations. Theory, practice and methods.

\title{
THE SPECIFICITY OF TECHNOLOGIES FOR FORMING POLITICAL IDENTITY BY NON-STATE ACTORS IN RUSSIA
}

\begin{abstract}
This article is analyzed the features of how non-state actors in Russia can form (or influence on the formation) a political identity. The genesis of approaches to the study of political identity is studied and the formation technologies are analyzed, which used in different historical periods in Russia are analyzed.

Key words: identity, political identity, formation of political identity, political parties, non-profit organizations, Russia.

Language: Russian

Citation: Gavrilov AD (2017) THE SPECIFICITY OF TECHNOLOGIES FOR FORMING POLITICAL IDENTITY BY NON-STATE ACTORS IN RUSSIA. ISJ Theoretical \& Applied Science, 06 (50): 107-111.

Soi: http://s-o-i.org/1.1/TAS-06-50-13 Doi: crossef https://dx.doi.org/10.15863/TAS.2017.06.50.13

\section{СПЕЦИФИКА ТЕХНОЛОГИЙ ФОРМИРОВАНИЯ ПОЛИТИЧЕСКОЙ ИДЕНТИЧНОСТИ НЕГОСУДАРСТВЕННЫМИ АКТОРАМИ В РОССИИ}

Аннотация: В данной статье анализируются особенности того, как могут формировать (или влиять на формирование) негосударственные акторы в России политическую идентичность. Изучается генезис подходов к изучению политической идентичности и анализируются технологии формирования, использовавшиеся в разные исторические периоды в России.

Ключевые слова: идентичность, политическая идентичность, формирование политической идентичности, политические партии, некоммерческие организации, Россия.
\end{abstract}

\section{Introduction}

Понятие политической идентичности имеет множество различных вариаций. Исследование О.В. Поповой показывает, что генезис изучения данного феномена в рамках политической науки на данный момент прошёл следующие стадии:

$\square$ На первом этапе (50-е-70-е гг. ХX в.) происходит отождествление политической идентичности с партийной самоидентификацией. «Первопроходцами» были американские учёные, среди которых отдельно выделяю исследователей из т.н. «мичиганского» проекта. Фактически, в тот период времени учёные искали способы привлечения электората через призму их восприятия действующей политики, и использовались в рамках предвыборных кампаний США, а позднее - и в европейских странах

$\square$ На втором этапе (с середины 70-х-90-е гг. XX в.) происходит смена вектора изучения: помимо партийных предпочтений, которые в тот период размываются у избирателей, анализируется всё то, что может повлиять на политическую идентичность вообще, и взаимосвязь с другими типами идентичности. Помимо этого, на исследования того периода оказывает влияние процесс глобализации, а также становление информационного общества,

«Третья волна» изучения политической идентичности приходится на 1990-е-2000-е гг. В рамках данного этапа учёные всё больше акцентируют внимание на т.н. «политике идентичности»: совокупности действий, которые позволили бы сформировать определённые политические идентичности. Во многом этому способствовало формирование европейской идентичности, а среди изучаемых аспектов актуализируются исследования потомков мигрантов и этнических меньшинств, а также влияние политической идентичности на крайние формы политического поведения [5, с. 14-24]. 


\begin{tabular}{|c|c|c|c|c|c|c|}
\hline Impact Factor: & $\begin{array}{l}\text { ISRA (India) } \\
\text { ISI (Dubai, UAF } \\
\text { GIF (Australia) } \\
\text { JIF }\end{array}$ & $\begin{array}{l}=1.344 \\
=0.829 \\
=0.564 \\
=1.500\end{array}$ & $\begin{array}{l}\text { SIS (USA) } \\
\text { PИНЦ (Russia) } \\
\text { ESJI (KZ) } \\
\text { SJIF (Morocco) }\end{array}$ & $\begin{array}{l}=0.912 \\
=0.234 \\
=3.860 \\
=\mathbf{2 . 0 3 1}\end{array}$ & $\begin{array}{l}\text { ICV (Poland) } \\
\text { PIF (India) } \\
\text { IBI (India) }\end{array}$ & $\begin{array}{l}=6.630 \\
=1.940 \\
=4.260\end{array}$ \\
\hline
\end{tabular}

\section{Materials and Methods}

В рамках отечественной политологии изучение данной тематики начинается в 90-х гг. XX в., как и развитие самой науки в целом, однако фрагментарные работы по отдельным аспектам, которые можно отнести к политической идентичности, появляются уже в 80-х гг. Изначально ряд работ были в русле «первой волны» (сама О.В. Попова отмечает, что это было характерно для стран постсоветского блока, поскольку там только образовывалась партийная система), однако в целом основными объектами исследования можно назвать политические ценности, политическое сознание и самоидентификация индивида. В нулевые годы XXI в. основные тренды в исследованиях примерно совпадают с «третьей волной» $[5$, с. 2426].

Таким образом, можно говорить о том, что с позиций генезиса изучения политической идентичности наблюдаются следующие подходы:

$\square$ Политическая идентичность
ассоциируется с партийной идентичностью,

$\square$ Политическая идентичность выступает как одна из идентичностей индивида,

$\square$ Политическая идентичность с точки зрения «политики идентичности».

Перейдём к определению политической идентичности. С точки зрения Г. Беста, который проводил исследование, в ходе которого сравнивал национальные идентичности стран Евросоюза по нескольким группам, политическую идентичность можно отнести «к эмоциональному компоненту политического сознания, фиксирующему представление человека о себе только в настоящем. Национальная идентичность имеет два аспекта этнический и общегражданский - и рассматривается как одна из разновидностей политической идентичности» [3]. Здесь можно заметить, что Бест отдаёт предпочтение национальной идентичности как некоей «основе», а политическая идентичность - лишь эмоциональное восприятие себя и политики в настоящее время.

В свою очередь, российский учёный И.С. Семененко считает, что политическая идентичность - это «комплекс идейнополитических ориентаций и предпочтений, которыми субъекты политического процесса наделяют себя и друг друга в процессе коммуникации, и предполагает отождествление носителя политической идентичности с тем или иным политическим сообществом. Она утверждается во взаимодействии с политическими институтами и реализуется в публичной сфере» [6, С. 10]. Обращает на себя внимание то, что определение Семененко относится скорее к коммуникативному подходу, и является, в сравнении с определением Г. Беста, отдельной от национальной, этнической или какой-либо иной идентичности.

Приведём ещё одно определение политической идентичности. И.Н. Тимофеев раскрывает политическую идентичность через три составляющие:

- Совокупность политических принципов, которые служат основанием для ответа на вопрос «Кто мы?», или, другими словами, осознание своей политической общности,

- Совокупность

политических представлений, которые задают у конкретного государства уникальную сущность через его соотнесение с актуальными «Другими» в логике оппозиции «Мы-Они», и через маркирование границ государства,

- Совокупность представлений о прошлом политического сообщества, исторических событиях, важных для граждан, а также осознание ими политической общности $[8$, С. 5].

На базе этого им даются следующие определения политической идентичности, которые соотносятся с каждой из составляющих:

1. Политическая идентичность «как политический проект, самоопределение коллективного политического Я, подчиняющий себе органические основания социального единства сообщества: язык, традиции, этническую культуру»,

2. Политическая идентичность как «механизм определения символических и ментальных границ политического сообщества, определение его уникальной сущности через соотнесение с актуальным Другим, через оппозицию Мы-Они»,

3. Политическая идентичность как комбинация «различных элементов истории и исторической памяти политического сообщества, структурированных в логике политического проекта и задающих содержание концепции коллективного политического Я» [8, С. 74].

Перейдём к технологиям формирования политической идентичности. Широкий спектр данных технологий был представлен в ряде работ Ю.В. Зевако. Он основан на историческом опыте России имперского, советского и постсоветского периодов. Остановимся подробнее на каждой из них.

Для имперского периода учёный выделяет следующие технологии и механизмы:

1. Технология «предписанной идентичности» (механизмы метрификации и 
«инородческого дискурса»). Она подразумевает градацию населения на основе различных параметров, в результате чего, по некоей совокупности отдельных параметров для индивида (или группы) «определялась» политическая идентичность и проводимая «политика идентичности»,

2. Технология «оптимального администрирования» (механизмы «административной унификации», «целевого управления», «инкорпорации элит» и «инфраструктурного соединения пространства»). Непосредственно связана с конкретными управленческими действиями со стороны государства, которые содействуют на обозначенной территории формированию определённой политической идентичности. Это можно пронаблюдать на примере административно-территориальной реформы времён Петра I, а также выстраивания единой системы чинов и строительство железных дорог в целом по стране (особенно до удалённых от столицы территорий) в XIX веке,

3. Технология «направленной социализации» (механизм русификации / обрусения). Подразумевает под собой непосредственное формирование определённой идентичности. В некотором смысле можно говорить, например, об унификации на заданной территории всей идентичности посредством системы образования, СМИ, культурным и конфессиональным доминированием,

4. Технология «финансово-бюджетного управления/регулирования» «позитивной/негативной (механизмы экономической дискриминации», «круговой поруки», «денежной интеграции»). Позволяет использовать различные экономические ресурсы в виде инвестирования, поощрения, или же конфискаций, к примеру, за успехи (или их отсутствие) в формировании политической идентичности. Кроме того, под этим может пониматься введение собственной валюты на обозначенной территории (и ограничение использования других валют, или их исключение) [12, с. 116-120].

В советский период указанные выше технологии и механизмы были дополнены такими, как:

1. Технология «общего дела» (которая включает в себя механизм «народной дипломатии»). Подразумевает под собой совместные действия на определённой территории. Например, это поддержка своих соседей, организация каких-либо локальных торжеств. Благодаря этому создаются связи между людьми на территории их проживания, при этом этническая составляющая постепенно нивелировалась тем самым «общим делом».,
2. Механизм «кадрового распределения» (он работает на стыке «метрификации» в рамках технологии «предписанной идентичности» и механизма «целевого управления» технологии «оптимального администрирования»). Исходит из административной составляющей формирования политической идентичности: профессионал из одной этнической группы «должен» работать в коллективе с представителями других этнических групп.,

3. Механизм «точечной секуляризации сознания» технологии «направленной социализации» [10].

Отдельно уделим внимание механизму «точечной секуляризации сознания». Под ней понимается выборочное удаление некоторых маркеров идентичности и замена их на другие. Ю.А. Зевако приводится в пример национальное самоопределение татар в постсоветский период. С этнической точки зрения «естественные» маркеры национальности, такие как язык и религия, к примеру, в советский период в целом были либо утрачены, либо в большинстве своём вытеснены в рамках формирования «советского гражданина». Соответственно, с распадом СССР и ростом «националистических дискурсов» встал вопрос о национальном самоопределении татар. Однако представители 30-40-летнего возраста (в период конца 1980-середины 1990-х годов) в большинстве своём не знали татарского языка, а также не были мусульманами. Вследствие этого в обозначенный период времени вставал ряд вопросов: можно ли считать татарином человека, который не знает татарский язык? Или же если он не является мусульманином [11, С. 150]?

В российский период Ю.В. Зевако и А.А. Вилков не выделяют каких-либо новых технологий формирования политической идентичности. Напротив, происходит использование прежних технологий. Однако это происходит лишь с нулевых годов XXI в., используя технологию «направленной социализации» [9].

На примере представленных выше технологий можно увидеть, что ряд из них в большинстве случаев может быть реализован только государством. И в первую очередь это связано с теми исключительными ресурсами, которые у него имеются. Речь идёт, например, о проведении политики на определённых территориях и её легальности и легитимности, о финансовых и законодательных ресурсах. Вместе с тем, насколько негосударственные акторы в России способны использовать те или иные технологии формирования политической идентичности? 
Здесь важно определиться с тем, что понимается под негосударственными акторами. С одной стороны, под это попадают субъекты гражданского общества. Но можно ли отнести к нему политические партии? С точки зрения «классического» определения можно говорить о том, что они входят в число негосударственных акторов [2, Р. 57]. Соответственно, переходим непосредственно к российской специфике.

На примере некоммерческих организаций в России видно, что любые попытки вести какуюлибо «политику идентичности» сводятся к риску быть включёнными в число организаций«иностранных агентов» или же «нежелательных организаций», поскольку некоммерческие организации не могут заниматься политической деятельностью [1, с. 331-333]. Аналогично можно говорить и про другие общественные объединения. Исследование О.В. Шиняевой и Л.Х. Каюмовой показывает, что россияне склонны не доверять некоммерческим организациям, и как следствие - влияние на население ограничено, и носит скорее локальный характер [7, с. 110-111]. А что касается политических партий, то их роль, в частности, хорошо описывает Симон Кордонский, который говорит, что политических партий фактически в России нет, есть лишь их «сословные имитации»: «А нет групп, чьи интересы можно было бы представлять. Вот этих, которые на площадь вышли? У них нет ничего общего, кроме обиды. Политическая партия - это институт классового общества. Партии представляют интересы богатых и бедных. А у нас нет богатых и бедных, у нас совсем другая социальная структура. И представительство осуществляется совершенно другим образом. На эту Думу возложены парламентские функции, которые она в принципе не может выполнять. Это еще не сословный собор, но это и не парламент» [4].

Вместе с тем, из представленных технологий в рамках НКО и политических партий возможны реализации каких-либо проектов или ведение совместной работы над чем-либо, что попадает под технологию «общего дела». А с точки зрения возможностей таргетированной рекламы в интернете, - реализация технологии «предписанной идентичности», несмотря на то, что это будет носить локальный характер. Однако это требует дополнительного исследования.

\section{Conclusion}

Таким образом, на сегодняшний день в России формированием политической идентичности в массовом порядке может только государство, в силу наличия соответствующих ресурсов и «полномочий». Проведение «политики идентичности» негосударственными акторами возможно лишь в локальном порядке, и применение соответствующих технологий формирования может носить лишь ограниченный характер. Однако с увеличением роли интернета есть вероятность того, что использование данного пространства позволит расширить потенциальную аудиторию для реализации «политики идентичности» в рамках того, как это видят соответствующие акторы.

\section{References:}

1. Gavrilov AD (2016) Spetsifika politicheskoy deyatel'nosti rossiyskikh NKO: kriticheskiy analiz // Voyennaya istoriya Rossii: problemy, poiski, resheniya: materialy III Mezhdunarodnoy nauchnoy konferentsii, posvyashchennoy 160-letiyu okonchaniya Krymskoy voyny 1853-1856 gg.: v 2 chastyakh. FGAOU VO «Volgogradskiy gosudarstvennyy universitet». Izd-vo: Volgogradskiy gosudarstvennyy universitet (Volgograd). 2016. - p. 329-335.

2. Goksel D, Gune N, Birden R (2005) The role of NGOs in the European integration process: The Turkish experience // South European Society and Politics. - 2005. - №10. - p. 57-72.

3. (2017) International Elites and the Formation of Political Identity in Post Soviet Space
[Elektronnyy istochnik] / Available: https://www.ucl.ac.uk/ceelbas/ceelbasnews/events/workshops/CN09CB1_Lane_Work shop , otkrytyy. Zaglo. s ekrana (Accessed: 08.03.2017).

4. Kak ustroyena Rossiya [Elektronnyy istochnik] Available:

http://rusrep.ru/article/2012/02/29/rossija/comm ents , otkrytyy, Zagl. s ekrana (Accessed: 14.06.2017).

5. Popova OV (2011) Razvitiye teorii politicheskoy identichnosti $\mathrm{v}$ zarubezhnoy i otechestvennoy politicheskoy nauke // Identichnost' kak predmet politicheskogo analiza. Sbornik statey po itogam Vserossiyskoy nauchno-teoreticheskoy 


\begin{tabular}{l|lrl|l|ll} 
& ISRA (India) & $=\mathbf{1 . 3 4 4}$ & SIS (USA) & $=\mathbf{0 . 9 1 2}$ & ICV (Poland) & $=\mathbf{6 . 6 3 0}$ \\
Impact Factor: & ISI (Dubai, UAE) $=\mathbf{0 . 8 2 9}$ & PUHL (Russia) $=\mathbf{0 . 2 3 4}$ & PIF (India) & $=\mathbf{1 . 9 4 0}$ \\
& GIF (Australia) & $\mathbf{0 . 5 6 4}$ & ESJI (KZ) & $=3.860$ & IBI (India) & $=\mathbf{4 . 2 6 0}$ \\
& JIF & $=\mathbf{1 . 5 0 0}$ & SJIF (Morocco) & $=\mathbf{2 . 0 3 1}$ & & \\
\hline
\end{tabular}

konferentsii (IMEMO RAN, 21 - 22 oktyabrya 2010). - M .: IMEMO RAN, 2011. - p. 13-29.

6. Semenenko IS (2011) Identichnost' v predmetnom pole politicheskoy nauki // Identichnost' kak predmet politicheskogo analiza. Sbornik statey po itogam Vserossiyskoy nauchno-teoreticheskoy konferentsii (IMEMO RAN, 21 - 22 oktyabrya 2010 g.). - M .: IMEMO RAN, 2011. - p. 8-12.

7. Shinyayeva OV, Kayumova LK (2015) Rol' nekommercheskikh organizatsiy $\mathrm{v}$ ukreplenii sotsial'noy integratsii rossiyan // Azimut nauchnykh issledovaniy: pedagogika $\mathrm{i}$ psikhologiya. - 2015. - №1. - p. 108-111.

8. Timofeyev IN (2008) Politicheskaya identichnost' v Rossii v postsovetskiy period: al'ternativy i tendentsii: monografiya / Mosk. gos. In-t mezhdunar. Otnosheniya (un-t) MID Rossii, kaf. polit. teorii. - M. : MGIMOUniversitet, 2008. - $176 \mathrm{p}$.

9. Vilkov AA, Zevako YV (2012) Tekhnologii formirovaniya politicheskoy identichnosti $\mathrm{V}$ sovremennoy Rossii // Izvestiya Saratovskogo universiteta. Novaya seriya. Seriya
Sotsiologiya. Politologiya. - 2012. - №4. - T. 12. - p. 62-71.

10. Zevako YV (2012) Formirovaniye politicheskoy identichnosti $\mathrm{v}$ Sovetskom Soyuze: tekhnologii, mekhanizmy, resursy // Molodozhnaya politicheskaya nauka $\mathrm{V}$ Saratove. Yezhegodnik nauchnykh statey po problemam politicheskoy teorii i praktiki studentov i aspirantov saratovskikh vuzov. Saratov, 2012. Vyp. 3. p. 22-32.

11. Zevako YV (2012) Tekhnologii formirovaniya politicheskoy identichnosti v sovremennoy Rossii: mekhanizmy, resursy, effektivnost': diss. ... kandidata politicheskih nauk: 23.00.02 / Yuliya Valer'yevna Zevako; [Mesto zashchity: FGBOU VPO Saratovskiy gosudarstvennyy universitet imeni N.G. Chernyshevskogo]. Saratov, 2012. - 209 p.

12. Zevako YV (2012) Tekhnologii konstruirovaniya politicheskoy identichnosti $\mathrm{v}$ polietnicheskoy srede Rossiyskoy imperii // Izvestiya Saratovskogo universiteta. Seriya: Sotsiologiya. Politologiya. - 2012. - T. 12. Vypusk 1. - p. 116-120. 